\title{
Asset Management Recovery after the Disaster: State of Knowledge
}

\author{
Maimunah Sapri ${ }^{1}$, and Siti Mariyam Abd Razak ${ }^{2}$ \\ ${ }^{1}$ Centre for Real Estate Studies, Universiti Teknologi Malaysia, 81310 UTM Johor Bahru, Johor, Malaysia \\ ${ }^{2}$ Faculty of Geoinformation and Real Estate, Universiti Teknologi Malaysia, 81310 UTM Johor Bahru, Johor, Malaysia
}

\begin{abstract}
Asset, infrastructure and business can be destroyed in a split seconds. It only takes a minute for natural disasters such as flood, hurricane and others to happen that will stop the business process and destroying the business as well as their assets. Late response towards the disaster will bring disastrous impact not only to the people but also the social and economic of the impacted people and area. It is therefore important for the organization to ensure speedy recovery of the disaster's impact such as the assets in an effort to ensure the business survival and facilitating societal and economic recovery. Therefore this paper examines the state of knowledge in relation to the asset management recovery especially after the disaster. Following to that, this paper will discuss the literatures involves in asset management recovery such as disaster management and business continuity plan (BCP). Towards the end, this paper suggests that the effect of lack of planning in asset management recovery will lead to an untold damage towards the community, organization as well as the business, taking months or even years to rectify. In some cases, businesses are shut down for goods due to loss data as well as other emerge problems cause by the disaster.
\end{abstract}

Keywords: Asset Management Recovery, Business Continuity Plan (BCP), Disaster Management, Flood

\subsection{Introduction}

Physically, Malaysia can be considered as one of the blessed countries because of its geographic location that prevents it from the threat of severe natural disaster like volcanic eruptions and cyclones [1]. However, it has its own fair share of the environmental perils such as flood. Malaysia is well known as a country that is prone to major flooding event that occurs once a year due to the northeast monsoon that bring heavy downpour. Due to its nature, lots of lives, assets, building, infrastructure and environment have been damaged. Although the disaster occurs in a split seconds but the impact that it leaves are tremendous and may take years to rectify. Moreover, the vulnerability of the community is increase when they choose to construct houses near the rivers and along the coastlines.

Nevertheless, due to its relative regularity that always appear from November to March each year made actions such as flood mitigation, forecasting and warning systems have been undertaken to minimize the impact of the disaster. However, despite numerous planning and preparation, it is believed that the present countermeasures are far from sufficient. This is shown in the recent management of the flood disaster that happen during December 2014 to January 2015 flood crisis. During the crisis, as many as 250,000 people need to be placed at the evacuation centre and great efforts have been taken to reduce the impacts that it caused such as the disruption of the victims life, the health issues, the polluted environment (due to the mud comes from the flood) and the massive costs encompass in the redevelopment of the assets and infrastructure. It is reported by [2] that the estimated costs of repair for the assets and redevelopment has exceed several billion of ringgit in expenses which is 10 times more higher than the usual amount spend despite the country's knowledge about the disaster and earlier preparation that have been carried out.

One of the factors that have been identified to lead to the situation is the ill-prepared systems to handle the post catastrophic impact of the disaster. Although the government has allocate the budget to rectify the impact but the actual preparation have not been carried out until the disaster occurs and thus resulted in the victims need to suffer the long terms effects of the disaster in particular to those whose house and business have been destroyed by the disaster [2]. The actions to rebuild was so delayed that even a year after the disaster, there are still victims who does not own house any house and still living in the tent provided during evacuation of the disaster. That is why it is important for the government to have a recovery plan that is design to assist them in recovery of their assets from the scratch so that people can recuperate faster and their misery is not prolonged.

In conjunction, to ensure the faster recovery of the victims to their normal lives, this paper discussed on the opportunity of asset management recovery to be used as one of the approaches to deals with the aftermaths of the disaster. According to [3], asset management recovery can be defined into three different but interrelated meaning. Firstly, it is an aims that involves the restoration of normal asset structures that were disrupted by the disaster exactly 
before the disaster struck. Secondly, it is considered as a phase in the disaster management cycle that begins with stabilization of the disaster conditions and end with the asset returned to its normal conditions. Thirdly, it is a process by which the asset achieves the goal of returning to its former condition.

It is undisputed that recovery after disaster is a gradual process which may takes either immediate, short, medium or a long term process. Nonetheless, the recovery activities on assets are often seen as a long term process due to the uncoordinated act that occurs concurrently and on certain occasion overlap or in conflict with one another. For example the community need to construct their temporary housing in Land A. But the land use for the land is industrial and that is conflicted with the local government. Due to that, a lot of times are wasted to change the current land use of the land towards residential use before the new development can be done. This difficult process will then lead to longer period of recovery for the victims. This situation occurs might be because of the fact that sometimes the responsibility to manage these activities is assigned to people who are unfamiliar with them [2]. Besides that, lack of understanding and awareness of the recovery plan are one of the factors that contribute to the disastrous impacts of disaster and make the recovery process harder [3-7]. That is why it is important for the community as well as the government to have knowledge about the disaster, what contribute to the disaster, its impact and how to recover once the disaster hit.

\subsection{Disaster management}

Disaster can be defined as a sudden or recurring event or incident that disrupts the normal activities or livelihood of people. It is an event that posed a dangerous threat to the safety of people, assets, buildings, infrastructure, and the environment when it occurs. In parallel, [6] believed that "disaster is an emergency situation that leads to the loss of life; it will damage properties and the environment and hinder the social and economic activities of people". In addition, [8] defines disaster as "a severe interruption of the community daily life due from people vulnerability towards the disaster impacts and involves loss of life as well as the assets which affect their ability to cope if it is left unaided". Matthew [5] explains that when disaster struck, it will affect the community and disable them to recover and pull through by using their own resources. Due to that, the community will need and require tremendous help and effort for them to get back on their feet and recover.

\subsection{Types of Disaster}

One of the steps in handling and dealing with the disaster is to know the types of disaster that may strike the community. It is important for the community to know the threat they are facing because different types of disaster lead to different scales of impacts.
Prior research agreed that there are two types of disaster $[5-7,9,10]$. The first one is the natural disaster and the other is the man-made disaster. According to [6], natural disaster is a catastrophic event that is formed through natural causes or it is also called as "the Act of God". It is something that man has no control over and nothing can be carried out to stop it from happening. Among the examples of natural disaster includes floods, earthquakes, cyclones, landslides, volcanic eruption, and tsunamis. On the other hand, man-made disasters are disasters that are caused by human activities whether due to mere negligence or irresponsible or reckless act. Among the example of man-made disaster are fires, accidents, nuclear explosions, toxic emissions, technological disaster, the collapsing of buildings and terrorism.

While many have agreed that disaster can be classified into major types of disaster but there is other researchers that claimed hybrid disasters or mix disasters should be also incorporated into the groups as well [1,11-13]. Hybrid disasters happens trough the mixture of both natural forces and human error. It can be explained through a simple example. When human decided to clear up the jungles (human error), there are fewer trees and roots to support the soil. Therefore, when there are heavy rainfalls (natural forces), soil erosion occurs and leads to landslides. Accordingly, it is important for the community to know types of disaster they might encounter to effectively and efficiently rectify the impact of the disaster especially in terms of physical assets.

\subsection{The Impact of Disaster}

Nowadays, the frequency of disaster occurs around the world are escalating. It is reported by United Nations that Asian countries were the most severely hit by the disaster. It is stated that there was a total of 11,985 natural disasters events take place around the world from 1970 to 2014. From that, 5,139 incidents took place in Asia and the Pacific. It was also reported that most frequent disaster faced by the Asia-Pacific was flood and storms, followed by tsunamis, earthquakes and landslides.

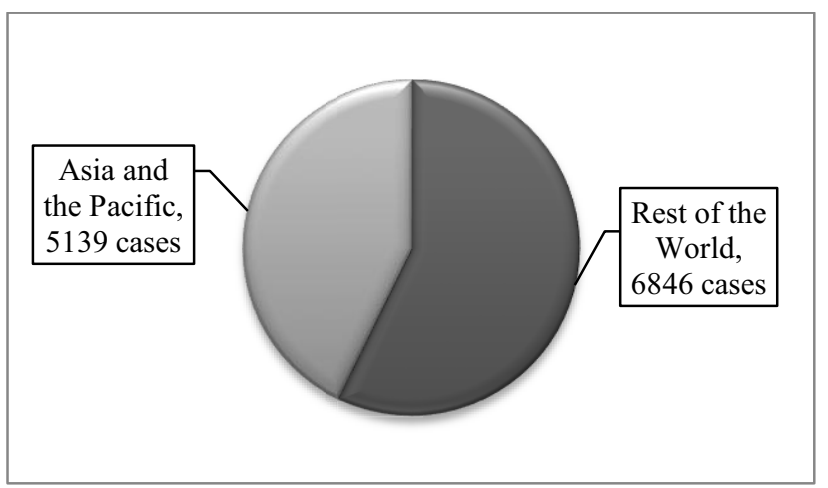

Figure 1. Total Occurrences of Natural Disaster Events from 1970 to 2014 (Source: [14]) 


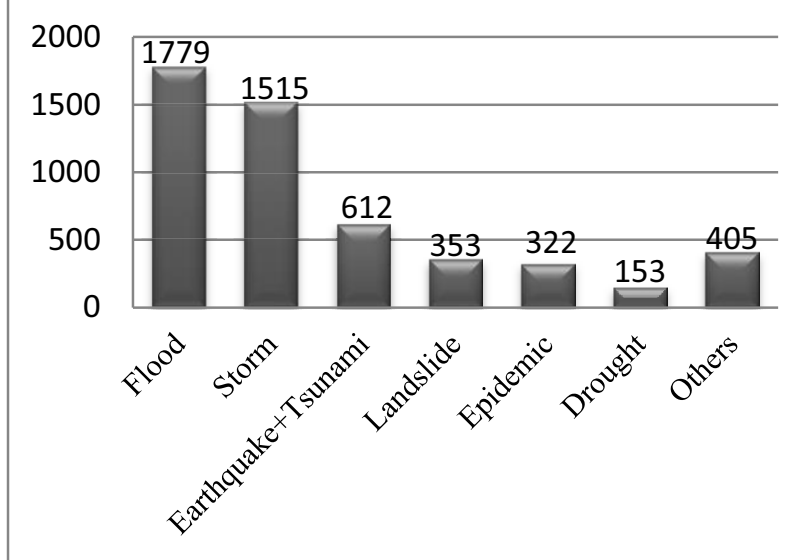

Figure 2. Occurrences of Natural Disaster Events in Asia and the Pacific from 1970 to 2014 (Source: [14])

In parallel, lots of losses have been reported in the form of human life and also physical damage that it caused to the surrounding area (assets and environment). Centre for Research of Epidemiology on Disasters (CRED) stated that disasters can be considered as one of the main threat to the whole world especially when the world is facing extraordinary scale of disasters over the years [15]. According to [7], between 1994 and 2003, there were more than 255 million of people were affected by the disaster. From that amount, 606,000 of lives were taken while leaving 4.1 million people injured and lots of building, assets and environment extremely damaged.

Table 1. Total number of natural disasters during 1974-2003 (Source: [7])

\begin{tabular}{lccccccr}
\hline & $1974-1978$ & $1979-1983$ & $1984-1988$ & $1989-1993$ & $1994-1998$ & $1999-2003$ & $1974-2003$ \\
\hline Africa & 88 & 113 & 128 & 107 & 149 & 333 & 918 \\
America & 99 & 199 & 255 & 319 & 320 & 475 & 1,667 \\
Asia & 220 & 336 & 353 & 482 & 449 & 726 & 2,566 \\
Europe & 43 & 108 & 136 & 144 & 134 & 288 & 853 \\
Oceania & 47 & 56 & 57 & 64 & 64 & 75 & 363 \\
World & 497 & 812 & 929 & 1116 & 1,116 & 1,897 & 6,367
\end{tabular}

Table 2. Total number of victims: people killed and affected, in millions from 1974-2003 (Source: [7])

\begin{tabular}{lrrrrrrr}
\hline & $1974-1978$ & $1979-1983$ & $1984-1988$ & $1989-1993$ & $1994-1998$ & $1999-2003$ & 1974.2003 \\
\hline Africa & 17.50 & 52.51 & 64.21 & 74.33 & 39.83 & 99.58 & 347.96 \\
America & 9.41 & 46.72 & 21.51 & 9.59 & 25.92 & 22.86 & 136.01 \\
Asia & 165.73 & 603.99 & 720.88 & 704.33 & 969.06 & $1,373.56$ & $4,537.54$ \\
Europe & 2.24 & 1.82 & 0.38 & 4.91 & 10.26 & 10.96 & 30.57 \\
Oceania & 0.10 & 0.68 & 0.71 & 7.32 & 10.30 & 0.27 & 19.38 \\
World & 194.98 & 705.72 & 807.69 & 800.48 & $1,055.37$ & $1,507.23$ & $5,071.46$
\end{tabular}

Table 3. Total economic damage in millions during 1974-2003 (Source: [7])

\begin{tabular}{lrrrrrrr}
\hline & $1974-1978$ & $1979-1983$ & $1984-1988$ & $1989 \cdot 1993$ & $1994 \cdot 1998$ & $1999 \cdot 2003$ & $1974 \cdot 2003$ \\
\hline Africa & 4,546 & 18,380 & 2,825 & 1,367 & 1,070 & 6,956 & 35,144 \\
America & 31,734 & 48,273 & 55,933 & 123,982 & 105,823 & 45,439 & 411,184 \\
Asia & 47,247 & 23,895 & 69,968 & 88,572 & 300,624 & 109,429 & 639,735 \\
Europe & 16,042 & 67,528 & 19,876 & 52,018 & 42,028 & 52,156 & 249,648 \\
Oceania & 8,631 & 15,504 & 1,947 & 9,097 & 5,337 & 2,711 & 43,227 \\
World & 108,200 & 173,580 & 150,549 & 275,036 & 454,882 & 216,691 & $1,378,938$
\end{tabular}

According to [3], the physical impacts left by the disaster are the most apparent, easy to measure and will be first reported by the media. Among the damage to the physical assets that can be easily spotted is the damage to the building (residential, commercial, and industrial), transportation system, infrastructure system (water, waste disposal, and electric power fuel), communication system, as well as the critical facilities (hospitals, fire stations, police stations, storage of critical records and etc.). Apparently, based on the research conducted by [16], the rates of damages towards the assets are increasing over the years especially in more developed countries. Physical damage to buildings is the most common form of damage and draws the most attention from the researchers. It is due to the fact that shelter is one the basic things that human need to survive. If it is not fulfilled, it will lead to physiological problems such as demotivation and it will eventually make it harder for people to recover from the impact of the disaster.

Aside from buildings, the damage to the transportation system also draws a lot of people attention. It is because the roads and bridges are considered as one of the weakest links in the transportation system. When disaster struck, the most likely damage to the transportation system is the bridge. Bridge act as a connector from one road to the other. When it is damaged or it cannot conduct it original function anymore, people will have problems to use it to go to the other side of the road. It is especially disturbing when helps needs to be delivered in time of the disaster. Moreover, when the transportation systems are disrupted, helps cannot be delivered to the required place and it will affect the search, rescues, and relief process during the disaster. Furthermore, all the research done on transportation believed that such interruption will contribute to business and economic loss following the disaster. [17] reported that 43 percent of business manager admit that their losses were partially caused by the disruption in the transportation system.

In addition to transportation disruption, damage to utility lifelines (gas, water systems and electricity) can also be one of the major sources of economic loss. A number of studies have shown that the effects of disruptions to these facilities create not only facility repair costs, but also revenue loss to the service provider, direct economic loss to consumers, and indirect economic loss to the region as a whole [18].

Other impacts of disaster include physiological and economic impacts towards the affected people. Dependable on that, [19] stated that due to the disaster the domestic violence cases increase by 50 percent and it also affects the mentality of the younger generation who is believed to have witnessed the death or severe injuries borne by the loved one during the disaster. In conjunction, lots of opportunities in terms of development and jobs are ceasing due to the inability of the business to recover. After all, [3] believed that 87 percent of the organizations do not have the confidence in their ability to fully recover after they were hit by the disaster especially the smaller enterprises. This is due to the lack of planning and the effects of the lengthier period for asset recovery which make them harder to operate their business. 


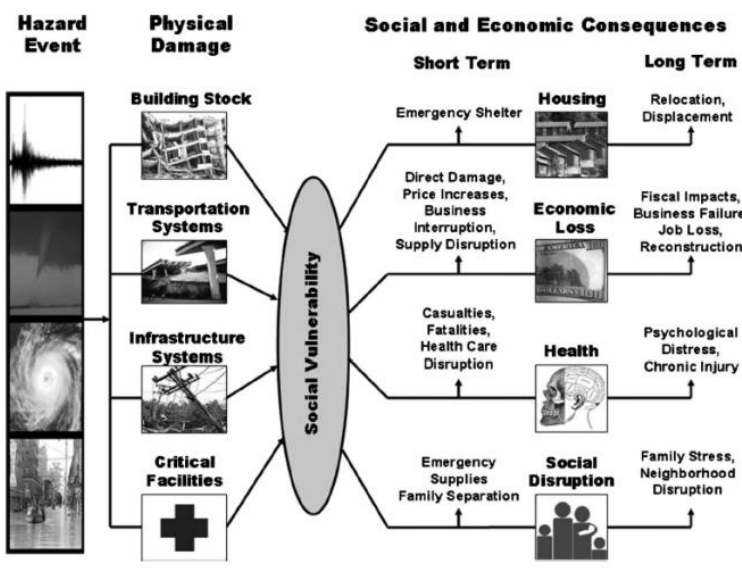

Figure 3: Conceptual Model of the Social and Economic Consequences of Disaster (Source: [20])

To boot, the weight of the disaster's impacts towards the community can also be measured through the community's vulnerabilities towards the disaster. Community's vulnerability is the ability of the community to forestall, survive, resist and recover from the impact of the disaster. Hence, the severity and the weight of the after effect of the disaster can be seen through the communities' capability to encounter the upcoming disaster as well as the effectiveness and efficiency of the current systems to respond towards the disaster. Corresponding to the prior research, the researchers found out that underprivileged people and less developed countries are the most vulnerable and exposed towards the impacts of the disaster $[12,13$, 21-24]. According to [12], impoverished people who are living in the less developed country are becoming more disaster-prone nowadays compared to the developed countries. It is due to multiple reasons of social, cultural, economic and political factors that force them to live in the disaster-prone areas that expose them to the impacts due to its unplanned urbanization and not moving on even though they know about the risks. Furthermore, in undeveloped countries that have a low average of gross national income, even a small loses matters as it will affect significantly in slowing down their development. However, it does not mean that developed countries are having less impact from the disaster. They are still facing loss in terms of the assets, infrastructure and lives but their ability to recover is much faster and effective with the proper disaster management plan to act as a defensive action against the catastrophic events.

\subsection{Approaches to Disaster Management}

Disaster needs to be managed as a defensive action in facing the calamity. Most of the disasters especially natural disaster cannot be prevented. Nevertheless, their result can be alleviated. Thus, by having a proper disaster management plan, unnecessary loss of lives and damages towards the assets and properties can be prevented or minimize.

According to [25], disaster management act as preliminary measures to deal with the disaster. It aids to lower down the risks by having a proper planning of what the community should do and how they should deal and react when disaster struck. It will assist and educate them generously on how to use available resources to get back on their feet and recover.

For that reason, currently there are quite a number of research have been undertaken in relation to disaster management. Many have discussed the definition, the stages of the disaster management, the process, the plan, the involvement of people, the use of technology and information as well as theoretical framework to assist in disaster management plan. However, according to [26], the most popular topic selected for the research is on the disaster management phases and process.

Prior research has argued and discusses on what are the actual phases of disaster management plan and they basically agreed that there are three fundamental timeline involve in determining the phases. They are pre-disaster phase which happens before the disaster, during the disaster phase and post-disaster phase which is after the occurrence of disaster and trying to get back to the previous condition [26-28]. These literatures then deliberate on the process for each timeline. Among the process involves are prevention, protection, preparedness, emergency actions and recovery.

Prevention, protection and preparedness are the phases that take place before the disaster happen (pre-disaster). It is the most common and popular research item and action to be taken by the community in assisting the effect of the disaster. It is due to the fact that preventive measures are vitals in reducing the risk of the disaster like the proverb saying 'prevention is better than cure" [29-32]. By knowing the risks each of the assets poses would make the recovery of the assets easier and the risks of them to be damaged are lesser when the disaster hit. For example, when regular inspection and risk assessment have been periodically carried out, the risks of them to deteriorate and malfunction are lesser and this will stop the building to easily collapse. It is parallel to the fact that collapsing building is one of the major disasters that cause a lot of casualties as well. Therefore, by having prevention plan, it will ensure the strengthening of its structure to protect the occupants and its contents. In addition, it is also important to protect the assets by having a regular and periodic maintenance plan that is conducted accordingly to ensure the ability of the assets to function as it was supposed to be are not declined. Meanwhile, preparedness also deals with the measures and activities that are taken in advance (before disaster) in ensuring effective and efficient response towards the impact of the hazards [21]. This includes the forecasting, issuance of early warnings before disaster struck, staff training, the delivery of knowledge regarding the disaster and its possible impact, preparation of the evacuation place and also the setting up of communities that involves in helping the affected people when disaster hit them [33].

Besides that, one the phases that caught people attention to study is on the emergency actions during the disaster. This is one of the vital subjects because lack of actions carried out in this stage might result in higher 
number of fatalities. Usually, at this stage emergency response plan and actions are needed to assist in dealing with the disaster aside from the search, rescues and relief operation. Therefore there are more studies carried out on how the response plan and rescues plan should be carried out.

Last but not least is the recovery phases after the disaster (post-disaster period). Recovery phase is one of the important phases that ensure the quality of lives of the community can be returned back as it was used to be. It refers to the decision and actions taken after the disaster with an intention to restore or improve the impact of disaster towards the community and at the same time, encouraging and supporting necessary actions to reduce the risk of the disaster [7]. In general, recovery involves the reconstruction of the damaged assets and continuation of the business process after the disaster as well as the ways of living before the disaster struck.

However, although it is one of the important process in disaster management plan, but there are limited research conducted on this topic. According to [7], the research on recovery has been overlooked despite a few contributions. The numbers of paper related to recovery of disaster management has record visible decrease throughout the years although there are several gaps are still remaining in an effort to have deeper understanding of disaster management theory. Among the common topics addressed in recovery phase is related to the temporary shelter (evacuation place), the funding and aid delivery system, impact assessment and resource management.

\subsection{Disaster in Malaysia}

Physically, Malaysia can be considered as one of the blessed countries because of its geographic location that prevents it from the threat of severe natural disaster like volcanic eruptions and cyclones [1]. Nevertheless, Malaysia did have its own fair share of the environmental perils in the form of floods, drought, periodic monsoon, and haze. Moreover, floods have been declared as the primary hazard that is affecting the country. What makes it worse is that it occurs on an annual basis following the Northeast Monsoon which predominates from November to March each year. The monsoon brings heavy rains and it escalated the average amount of rain to $2,500 \mathrm{~mm}$ a year and indirectly makes Malaysia as one of the countries that received heaviest rainfall in the world. Besides, flash flood that occurs occasionally is also one of the worrisome hazards that cause discomfort towards the community due to its impact on the assets and environment. Likewise, according to [1], it has been reported in the last couple of decade that the incidents has increase in terms of its frequencies and magnitudes and it is sometimes unexpected.

Currently, it has been estimated that at least 3.5 million of people in Malaysia are living in the flood prone area for varying reasons [34]. According to [35], the reasons they are drawn to the area are because of soil fertility and undeveloped land. Although they know of the existing risks, but factors such as financial ability always hinder them from moving to the safer places. For some people, the choice to move on and relocate to other place is simply does not exist and lead them more vulnerable and exposed towards the impacts of disaster [13].

Once disaster struck, the tangible and intangible impacts are clearly seen in terms of the damage to the physical assets. During the past floods events, few gross estimates have been made in terms of the costs of damage to private properties, businesses and industries and it is found out that these costs are substantial. The calculation of these losses includes both the tangible and intangible losses as well as the direct and indirect losses. For example, [36] found out that the average loss per household that is inflicted with the disaster is about RM1, 393 in 1993. This figure may not appear to be high for the people with a high income but the problem arise when nearly half of the household had a monthly income of RM500 and below. Thus, the loss has become so significant to them and this affects their ability to recover and increase their vulnerability towards the impact of the disaster.

At the same time, the business operation also suffers similar fate. It is reported that nearly half of the business operation need to be closed down due to their inability to recover from the impact of disaster [13]. Some of the reason is because they do not have the constructive plan of business continuity management that enable them to strategize on what they need to do if the business is disrupted. Besides that, the failure and damages occurs to the assets and the extended period of its recovery also plays a vital part in hindering the recovery operations of the business. That is why, it is important for the government to know how these assets can be recovered not only for the survival of the affected people but also for their continuity of living as before the events occur.

Currently, Malaysia has developed the National Security Council (NSC) Directive 20 that was issued to give guidelines on how the disaster should be managed but Centre for Public Policy Studies (CPPS) stated that the system is so ill-prepared to handle the post-flood catastrophes. Although NSC Directive 20 has allocate budgets and plans for recovery, but the actual preparations have not been made up until disaster happen. It means that the plan is just on paper without actions taken to conduct it. Ultimately, the victims are left stranded and in due course suffers the long terms effect of disaster in particular to those whose homes and business have been destroyed.

Besides, the recent disaster like earthquakes and tsunamis that unexpectedly occurs in Malaysia have decrease the resilience of community towards the impact of disaster due to the fact that the building in Malaysia are not build to withstand such impact from disaster. Because of its rarity, lots of building and infrastructure collapse like the one recently occur in Sabah. Due to the lack of 
research and planning as well as factors like unexpected events, it takes months before the problems could be effectively rectified. Hence, it makes the recovery process much harder and longer.

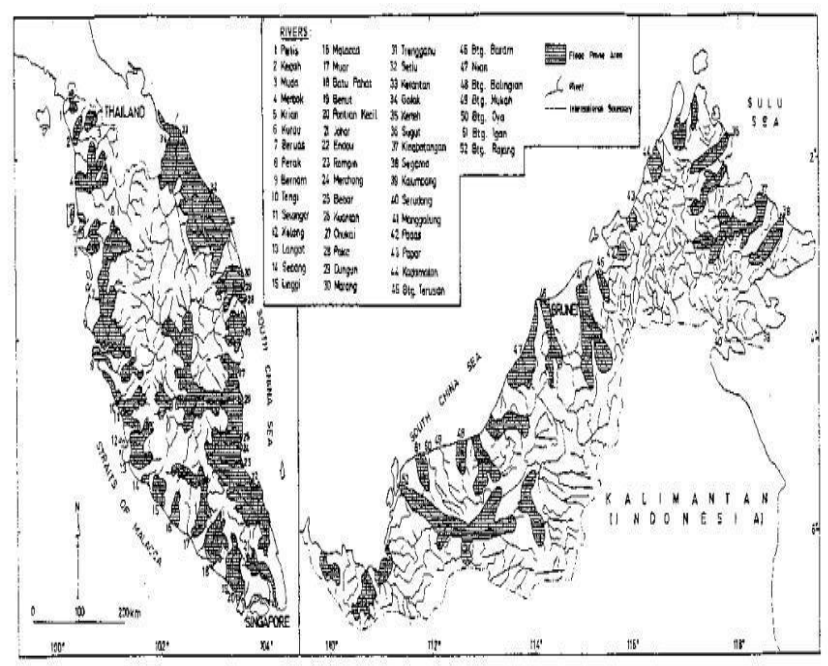

Figure 4. Approximate Distribution of Flood Prone Areas in Malaysia (Source: [35])

\subsection{Asset Management}

Assets can be defines as any entity that can be used to produce goods, products or services to meet the needs, expectation and requirements of a client or customer [37]. Assets can be divided into three major categories which are discrete assets, linear or continuous assets and virtual assets. Discrete assets can be seen in the form of pumps, packaging lines, buildings, and vehicles. In the interim, linear or continuous assets are water pipes, sewer, roads, land and also electric transmission lines while virtual assets are software.

In the meantime, asset management can be defined as a holistic process that provides guidance in the management of these assets throughout its life cycle from the acquisition of the assets, operation until it's time for disposal. As assets exist to support the business and fulfilled the needs, expectation and requirements of people, it is anticipated to make the most of their life period to carry out their function while managing the related risks and costs accustomed to it throughout their lifecycle. According to [37], all of these assets will go through phases of life cycle starting from evaluation, strategy, planning, design, creation, operation or maintenance, modification, and lastly disposal. Evaluations are done to look at the needs of the assets. The organization must thoroughly examine the need for assets and consider the full range of options before responding to it. It is to ensure they thoroughly need the assets and the assets are created based on the requirements of the stakeholders. After evaluation has been carried out, the next thing to be done is to strategies. Without proper planning conducted the asset manager might make a mistake that will affect the aims of the organization.
Therefore, planning need to be considers and carefully planned by the asset manager to assist the organizations needs and eventually ensure that the asset can eventually aid in value adding of the organization. This will lead to the design process where the assets will be design based on the need of all the stakeholders and the requirements of the company to achieve its objectives.

Next is the creation of the assets. In achieving successful creation of an asset it is important to focus on time, scope, money and the facility impact [37]. It is important for the organization to follow their own purchasing terms and guidelines in the sourcing, selection and procurement of any assets, components or materials that will be used for the assets.

After the creation of the assets, the next step is operation and maintenance. Time, money and effort must be spent by the asset manager or the involve parties to maintain the value of an asset such as the building and at the same time providing the occupiers with a satisfactory environment [38]. To do this, expertise is needed to do maintenance works but management also plays an important part so that the works is planned economically and effectively. For years maintenance has been acknowledge as an important works to be done to prolong the lifespan of an asset and ensuring that the asset is in a good conditions. It is also being recognized as an investment that can show some economic return and also the area where the owner can cut the cost for maintenance works especially during the recent economic conditions. So to make sure that returns will be regained a proper maintenance management is needed. Hence, there are basically four matters to be considered for asset management. They are planned maintenance, unplanned maintenance, and maintenance of asset records, and reassessment. Meanwhile, Disposal of the asset generally will occur due to the changes in the needs and demand of the asset. To know that, assessment of the need for assets can be carried out to determine whether the needs and expectation of the customers is fulfilled. Thus, the organization would know whether the asset is still viable to generate profits and effectively use by their customers.

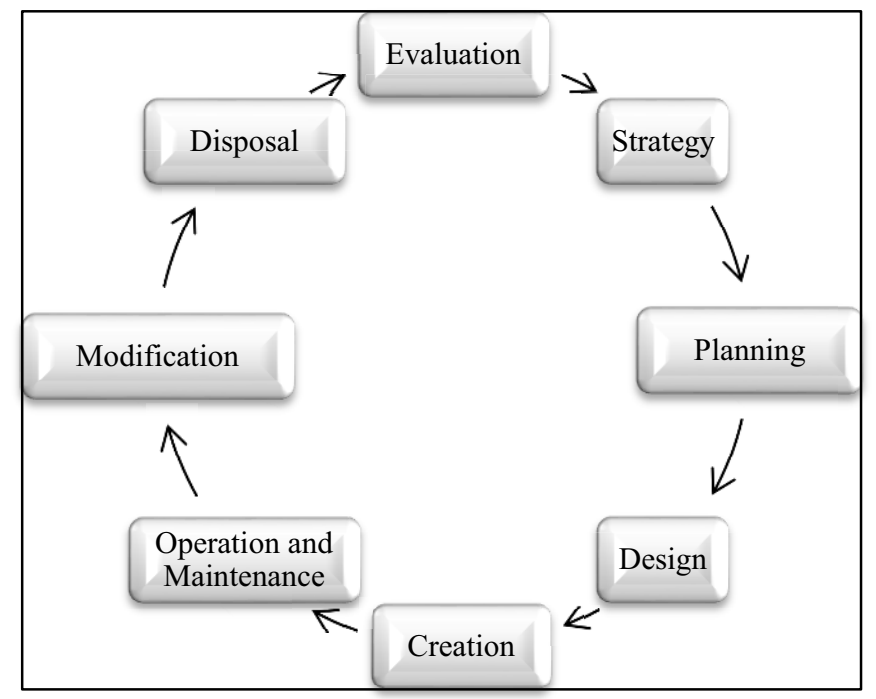

Figure 5. Asset Life Cycle 


\subsection{Asset Management Recovery}

Recovery is a process to reclaim life or previous (normal) condition of life before something unwanted happen. In the case of disaster, "something unwanted" is the disaster and recovery means the restoration of the community way of life before the disaster occurs. According to [38], recovery can be defined based on a comparison between an indicator of the time path which is "with" and "without" disaster or between "before" and "after" disaster. Based on that, it is best to assume that recovery planning can be done way before disaster while effective recovery actions can be conducted after the disaster. After the disaster, inspections need to be conducted in the impacted area to know the involved damage to the assets, building and infrastructure. That is why it is important for asset management recovery to be embedded in the disaster management plan for the community as it will assist the community on the total numbers of assets exist before the disaster, the requirements for the asset and how to recover it from the scratch. It is because asset management starts from the very beginning of the assets life cycle. Hence, when a disaster occurs, the organization will know all the details regarding the assets.

Among the objectives of assets recovery is to minimize loss and downtime as well as to ensure the continuity of lives and business. However, when longer time are needed to recover especially for the assets such as buildings and infrastructure, the longer the times that it take for the community and business to get back to their normal live. After all, when disaster strike, recovery and response activities are usually uncoordinated because of the tension and panic arise. Therefore what should occur concurrently becomes overlap and conflicting with one another [3]. In some cases, management responsibility to handle the impact of disasters is often given to the people unfamiliar with them due to reasons such as the appointment of new leader, the persons elected are not familiar with disaster and so forth. The concern is that, the community might miss their chance to improve the assets, infrastructures, the environment and quality of life due to that minor glitch.

Over the years, there is research conducted on how to improve the recovery process such as research on funding and aid delivery system [33], reconstruction of flood resistance shelter [22, 24, 39], impact assessment and resource management [30]. Aside from that, there is also research carried out suggesting on the quality infrastructure to be built to replace the existing prone-disaster buildings and infrastructure. However, realizing infrastructure reconstruction with the best quality has proven to be quite difficult for developing countries [21]. Besides that, the government need to consider the reluctance of community to move from the area that they have considered as home even through there are better places have been built for them. It is therefore important for the government to have a guidelines or reference on how the area and the assets can be rebuilt and recover as quickly as possible.

However currently there are no studies on how the assets can be rebuilt from scratch. Hence, this situation creates a gap in this area. From the past disaster, there is evidence whereby lack of planning in the asset recovery matter has caused one of the schools in Kuala Krai to not be able to serve its main objectives which is to deliver teaching and learning process effectively. Even though, the school period has started in January but until April 2015 , there are still students who are incapable to come to the school because of the damaged in the school facilities such as the hostels are not yet rectified. Due to that, it is important for the government and the community to know how the assets can be rebuilt so that they can participate and help in the recovery process to minimize the time of recovery.

\subsection{Business Continuity Plan (BCP)}

$\mathrm{BCP}$ is a comprehensive organizational plan that includes in the disaster asset management recovery plan. By having $\mathrm{BCP}$ in asset management recovery plan, the community can prepare on the things that they would need to do in ensuring the on-going of the business even after the disaster. It is because, asset, infrastructure and business can be destroyed in a split seconds. Although in order to have a successful business, one need to do lots of things such as analysing the market, identifying the potential customers, creating strategies for delivering the products and services and establishing financial goals [40]. However, despite their efforts, it can take less than 60 seconds for a company's reputation to be ruined and its business to be crippled [41]. In just 60 seconds a server failure might occur or hacker can strike out the essential applications and lead to a disastrous series of events. In the worst case, natural disasters such as floods, hurricane and others might just happen and stop the business process and destroying the business as well as their assets [40, 42-44]. It is therefore important for the organization to ensure the continuity of the business activity following the disaster to ensure the business survival and facilitating societal and economic recovery [43]. According to [41], the effect of lack of planning recovery to face the disaster will lead to an untold damage to a company's reputation, taking months or years to rectify. In some cases, the businesses are just shut down for goods due to the loss of data as well as other emerge problems cause by the disasters [45]. A study made by Datapro Research Company found out that 43 percent of organisation strike by disaster will never recuperate and reopen and another 29 percent fail within two years [45]. Thus, it is important for the companies to have Business Continuity Plan (BCP) to ensure the continuity of their business and activities despite all the business disruption.

$\mathrm{BCP}$ is designed to avoid or mitigate the risks or in other words to reduce the impact of crisis [46]. According to [47], BCP is "a sound plan that will ensure that the business recovers from a disaster faster in an effective and efficient manner, and simultaneously business disruption and damage can be minimized and managed". [40] illustrates BCP as "the method and procedures that need to be used by the organization to ensure that important function of the business can be carry on in and after the disaster". Meanwhile, [43] defines BCP as a proactive and holistic management process designed to facilitate the continued achievement of critical business objectives. It is 
due to the facts that it provides an iterative and structured process that incorporates risk identification, assessment, and management, the development of disaster recovery plans and procedures, training, exercising, and using feedback that they received to promote an iterative development of plans and capabilities. BCP is develop to gain an understanding on what the organization must achieves (critical objectives), identifying the barriers or interruptions that may prevent their achievement, and determining how the organization will continue to achieve these objectives when interruptions occur [43]. Therefore, the organization can ensure that the business can continue as stable as possible as it was before and enable them to handle the crisis as well as attain revenues throughout the days.

According to [40], among the benefits of BCP includes reduce financial costs, enhance customers service, and improve the ability of the organization to face undesirable events such as natural disasters and ensuring they can get back to their business activity the same as the before the disruption happen.

\section{Conclusion}

Malaysia is well known as a country that faces several flood events in an annual basis. Although the knowledge is there, but the preparation to face the impact are less than sufficient (CPPS, 2015). This event causes the impact such as the physical damage to the buildings and asset to take longer times to rectify and somehow becomes a barrier to the victims to restore back their normal lives.

One of the reasons identified to cause the situation is the lack in the recovery planning actions. The standard operation of procedures (SOP) is not well prepared and the related agencies failed to understand on the items that they should do to help in the recovery process. Thus, it is important for a more detailed plan to be design to help the community as well as the government to know on their roles and responsibilities as well as their limitation and scopes each one of them need to conduct to the ensure the smooth running of recovery process.

This is where asset management recovery comes in handy. Through the plan, the government will know what to do with the assets from the scratch even if the assets are completely destroyed. Asset management recovery plan will assist the community and the government even through it is handed to the person who is unfamiliar with the disaster because of the complete guidelines and reference on what is their roles and what they need to do. This is important to ensure that the destroyed asset can be recover as fast as it can to ensure the quality of life and business can be continued like before the disaster strike or even better.

\section{Acknowledgement}

This research is supported by the Ministry of Education, Malaysia under Fundamental Research Grant Projects (FGRS) (VOT: 4F633).

\section{References}

[1] B. A. Rahman, Issues of Disaster Management Preparedness: A Case Study of Directive 20 of National Security Council Malaysia, IJBSS, Vol. 3 Iss 5 pp. 85-91 [2012]

[2] Centre for Public Policy Studies (CPPS), CPPS Policy Fact Sheet: Malaysia's Flood Management, CPPS, Kuala Lumpur, Malaysia [2015]

[3] M. K. Lindell, Recovery and Reconstruction after Disaster, Texas A \& M University, College Station, TX, USA [2011]

[4] P. R. Berke and T. Beatley, After the Hurricane: Linking Recovery to Sustainable Development in the Caribbean, The John Hopkins University Press. Baltimore and London [1997]

[5] P. E. G. Matthews, Disaster Management in Libraries, LIBR J, Vol. 17 Iss 3 pp. 5-12 [1996]

[6] I. M. Shaluf, F. R. Ahmadun, Disaster Types in Malaysia: An Overview, Disaster Prev. Manage., Vol. 15 Iss 2 pp. 286-298 [2006]

[7] T. L.M. F. G. S. S. M. Mueller, Balanced Scorecard for Natural Disaster Management Projects, Disaster Prev. Manage.: An International Journal, Vol. 16 Iss 5 pp. 785-806 [2007]

[8] Department for International Development (DFID), Disaster Risk Reduction: A Development Concern, DFID, London [2004]

[9] B. A. Turner, N. F. Pedgeon, Man Made Disaster, $2^{\text {nd }}$ ed. Butterworth-Heinemann, Oxford [1997]

B. Richardson, Socio-Technical Disaster: Profile and Prevalence, Disaster Prev. Manage., Vol. 3 Iss 4 pp. 41-69 [1994]

[10] C. Hood, M. Jackson, the New Public Management: A Recipe for Disaster in D. J. Parker and J. W. Handmer, Hazard Management and Emergency Planning, Perspective on Britain, Chapter 9, James and James Science Publishers Ltd, London [1992]

[11] M. Shaluf, An Overview on Disasters, Disaster Prev. Manage., Vol. 16 Iss 687-703 [2007]

[12] G. S. J. Kumar, Disaster Management and Social Development, Int. J. Sociol. Soc. Pol., Vol. 20 Iss 7 pp. 61-81 [2000]

[13] G. O'Brien, P. O'Keefe, J. Rose, B. Wisner, Climate Change and Disaster Management, Disasters, Vol. 30 Iss 1 pp. 64-80 [2006]

[14] United Nations: Economic and Social Commission for Asia and the Pacific, Overview of Natural Disasters and their Impacts in Asia and the Pacific, 1970-2014, Disaster Risk Reduction Section, ICT and Disaster Risk Reduction Division, ESCAP [2015]

[15] Department for International Development [DFID], Reducing the Risks of Disaster-Helping to Achieve Sustainable Poverty Reduction in a Vulnerable World, A DFID Policy Paper, DFID, London [2006]

[16] P. R. Berke, Natural Hazard Reduction and Sustainable Development: A Global Assessment, J. Plan. Lit., Vol. 9 pp. 370-382 [1995]

[17] F. L. Bates, W. G. Peacock, Living Conditions, Disaster and Development: An Approach to Cross-Cultural Comparisons, Athens, GA: University of 
Georgia Press [1993]

[18] A. Rose, D. Limb, Business Interruption Losses from Natural Hazards: Conceptual and Methodological Issues in the Case of the Northridge Earthquake, Environmental Hazards, Vol. 4 pp. 1-14 [2002]

[19] B. H. Morrow, Hurricane Andrew: Ethnicity, Gender and Sociology of Disaster, London, Routledge pp. 141-170 [1997]

[20] French, S.P., Lee, D. \& Anderson, K, Estimating the Social and Economic Consequences of Natural Hazards: Fiscal Impact Example, Natural Hazards Review, 11(May), pp.49-57 [2010]

[21] R. Palliyaguru, D. Amaratunga [2008], Managing Disaster Risks through Quality Infrastructure and Vice Versa, Structural Survey, Vol. 26 Iss 5 pp. 426-434

[22] B. Wisner, J. Adams, Environmental Health in Emergencies and Disasters: A Practical Guide, World Health Organization, Geneva [2003]

[23] C. Benson, J. Twigg, M. Myers, NGO Initiatives in Risk Reduction: An Overview, Disasters, Vol. 25 pp. 199 [2001]

[24] K. S. Vatsa, Risk, Vulnerability, and Asset based Approach to Disaster Risk Management, Int. J. Sociol. Soc. Pol., Vol. 24 Iss 10/11 pp. 1-48 [2004]

[25] F. Nateghi-Alahi, Y. O. Izadkhah, Earthquake Disaster Management Planning in Health Care Facilities, Disaster Prev. Manage., Vol. 13, Iss 2 pp. 130-135 [2004] [26] E. Lettieri, C. Masella, G. Radaielli, Disaster Management: Finding from a Systematic Review, Disaster Prev. Manage. Vol. 18 Iss 2 pp. 117-136

[27] T. Hensgen, K. C. Desouza, G. D. Kraft, Games, Signal Detection, and Processing in the Context of Crisis Management, J. Conting. Crisis Manag. Vol. 11 Iss 2 pp. 67-77 [2003]

[28] R. Bertrand, C. Lajtha, A new Approach to Crisis Management, J. Conting. Crisis Manag. Vol. 10 Iss 4 pp. 181-191 [2002]

[29] S. Menoni, F. Pergalani, An attempt to Link Risk Assessment with Land Use Planning: A Recent Experience in Italy, Disaster Prev. Manage., Vol. 5 Iss 1 pp. 6-21 [1996]

[30] F. C. Dai, C. F. Lee, Y.Y. Ngai, Landslide Risk Assessment and Management: An Overview, Eng. Geol., Vol. 64 Iss 1 pp. 65-87 [2002]

[31] P. G. Bakir, Proposal for A National Mitigation Strategy Against Earthquakes in Turkey, Nat Hazards, Vol. 33 Iss 3 pp.405-425 [2004]

[32] S. Mansor, M. Abu Shariah, L. Billa, I. Setiawan, F. Jabar, Spatial Technology for Natural Risk Management, Disaster Prev. Manage., Vol. 13 Iss 5 pp. 364-373 [2004] [33] K. M. Sukeri, S. Shazwani, Flood Disaster Management in Malaysia: An Evaluation of the Effectiveness Flood Delivery System, IJSSH, Vol. 5 Iss 4 pp.398-402 [2015]

[34] N. W. Chan, Flood hazard mitigation in peninsular Malaysia, in P.A. Merriman and C.W.A. Browitt, Natural Disasters: Protecting Vulnerable Communities, Proceedings of IDNDR Conference in London, Thomas Telford, London, 13-15 October 1993, pp. 194-209 [1993] [35] W. C. Ngai, Increasing flood risk in Malaysia: causes and solutions, Disaster Prev. Manage.: An International Journal, Vol. 6 Iss: 2, pp.72 - 86 [1997]
[36] N. W. Chan, A contextual analysis of flood hazard management in peninsular Malaysia, unpublished $\mathrm{PhD}$. thesis, Middlesex University [1995]

[37] R. Lutchman, Sustainable Asset Management: Linking Assets, People and Processes for Results. DEStech Publication [2006]

[38] S. B. Miles, The Role of Critical Infrastructure in Community Resilience to Disasters. Structures Congress $2011 @$ ASCE 2011,pp.1985-1995 [2011]

[39] G. Ma, B. S. C Fung, China's asset management corporations. BIS Working Paper, (115) [2002]

[40] A. J. Karim, Business disaster Preparedness: An Empirical Study for Measuring the Factors of Business Continuity to face Business Disaster, IJBSS, Vol. 18 Iss 18 pp. 183-192 [2011]

[41] R. Stanton, Beyond disaster recovery: the benefits of business continuity. Computer Fraud \& Security, Vol. 7 pp.18-19 [2005]

[42] W. Lam, Ensuring Business Continuity, IT Pro, pp.19-25 [2002]

[43] D. Paton, Business Continuity During and After Disaster: Building Resilience through Continuity Planning and Management. ASBM, Vol. 1 Iss 2 pp.1-16 [2009]

[44] K.N Myers, Total Contingency Planning for Disasters : Managing Risk, Minimizing Loss, Ensuring Business Continuity, The Internal Auditor, Vol. 51 pp.1415 [1994]

[45] V. Cerullo, M. J. Cerullo, Business Continuity Planning: A Comprehensive Approach. Inform. Syst. Manage., Vol. 21, pp.70-78 [2004]

[46] C. Castillo, Disaster preparedness and Business Continuity Planning at Boeing: An integrated model, JFM, Vol. 3 Iss 1, pp.8-26 [2004]

[47] M. Savage, Business Continuity Planning, Work Study, Vol. 51 Iss 5 pp. 254-261 [2003] 